
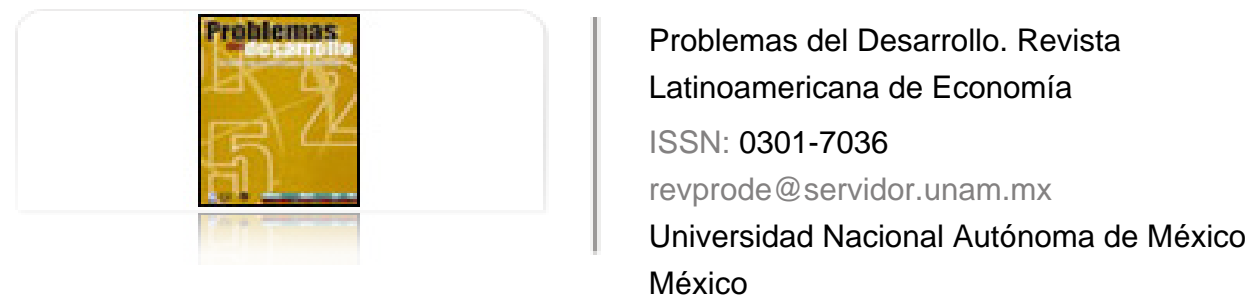

Ramírez Cedillo, Eduardo

El gobierno como empleador de última instancia: una alternativa de programa público de empleo (PPE)

Problemas del Desarrollo. Revista Latinoamericana de Economía, vol. 37, núm. 144, enero-marzo, 2006, pp. 171-191

Universidad Nacional Autónoma de México

Distrito Federal, México

Disponible en: http://www.redalyc.org/articulo.oa?id=11820097008

Cómo citar el artículo

- Número completo

- Más información del artículo

Página de la revista en redalyc.org

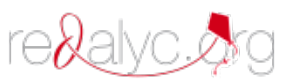

Sistema de Información Científica

Red de Revistas Científicas de América Latina, el Caribe, España y Portugal Proyecto académico sin fines de lucro, desarrollado bajo la iniciativa de acceso abierto 


\section{EL GOBIERNO COMO EMPLEADOR DE ÚLTIMA INSTANCIA: UNA ALTERNATIVA DE PROGRAMA PÚBLICO DE EMPLEO (PPE)*}

\section{Eduardo Ramírez Cedillo**}

Fecha de recepción: 19 de septiembre de 2005. Fecha de aceptación: 27 de enero de 2006.

\section{Resumen}

Ante el creciente nivel de desocupación laboral y la imposibilidad de creación de empleos por parte de la iniciativa privada, se hace necesario que el gobierno establezca un programa de empleo público que pueda incentivar la reactivación económica. El desempleo es seriamente costoso para una economía y resulta ilógico que, teniendo la posibilidad de disminuirlo, no se instrumente un plan gubernamental con ese fin. La razón para no crearlo encuentra al menos dos impedimentos: la escasez de recursos para llevarlo a cabo y la posibilidad de que pueda resultar inflacionario. Con este documento se intentan aportar argumentos a favor de un programa de empleo público que arroje necesariamente más beneficios que los perjuicios que le puedan ser imputados.

Palabras clave: empleo, desempleo, gasto de gobierno, inflación, deflación.

\section{Abstract}

Given the growing rate of unemployment and the impossibility of creating jobs via private enterprise, it is necessary that the government establish a program of public employment able to promote economic reactivation. Unemployment is extremely costly for an economy and it is illogical that, when it is possible to reduce it, no government program is implemented to deal with it. The reason for not creating it has to do with two impediments: a scarcity of resources to carry it out and the possibility that it may lead to inflation. This paper seeks to provide arguments in favor of a public employment program that necessarily gives rise to more benefits than the prejudices which may be imputed.

Key words: employment, unemployment, government spending, inflation, deflation.

* El presente artículo fue posible gracias al apoyo de la beca que, para realizar estudios de doctorado, fue otorgada al autor por el Consejo Nacional de Ciencia y Tecnología y por la Dirección General de Estudios Profesionales (DGEP UNAM).

** Profesor de asignatura en la Facultad de Contaduría y Administración UNAM y profesor en la especialidad de Derecho Fiscal, UNITEc. Direcciones electrónicas: ramceed@prodigy.net.mx y ramceed@hotmail.com 


\section{Résumé}

Face au croissant niveau de chômage et à l'impossibilité de création d'emplois de la part de l'initiative privée, l'établissement d'un programme d'emploi public qui puisse encourager la réactivation économique par le gouvernement devient nécessaire. Le chômage résulte sévèrement onéreux pour une économie et il est donc illogique qu'on ne mette pas en œuvre un plan gouvernemental, si on a la possibilité de le faire diminuer. La raison pour ne pas mettre en place ce plan trouve au moins deux empêchements: l'exiguïté des ressources et la possibilité qu'il puisse résulter inflationniste. Avec ce document ont essaye d'apporter des arguments en faveur d'un programme d'emploi public qui jettera nécessairement plus de bénéfices que de préjudices.

Mots-cléfs: emploi, chômage, dépense de gouvernement, inflation, déflation.

\section{Resumo}

Por causa do grande nivel de desemprego e à impossibilidade da criação dos mesmos por parte da iniciativa privada, é preciso que o governo estabeleça um programa de emprego público que possa incentivar a reativação económica. O desemprego resulta seriamente custoso para uma economia e resulta ilógico que, tendo a possibilidade de o diminuir, não se tenha um plano governamental para tal propósito. A razão para não criá-lo enfrenta pelo menos dois impedimentos: a escassez dos recursos para o efetuar e a possibilidade de que possa resultar inflacionário. Com esse documento se tenta aportar argumentos a favor dum programa de emprego público que traga necesariamente maiores beneficios do que prejuizos que lhe possam ser imputados.

Palavras chave: emprego, desemprego, gasto de governo, inflação, deflação. 


\section{Introducción}

$\mathrm{E}$

1 desempleo es una enfermedad que no ha podido ser solucionada mediante la política económica aplicada desde la década de los ochenta. ${ }^{1}$ Sin importar cuánto

se diga al respecto de que México avanza en la solución de ese mal, lo cierto es que cada vez es más crónico y tiene como secuela el incremento de la pobreza en la población. ${ }^{2}$ Quizá el problema para erradicar la "enfermedad" consiste en un diagnóstico equívoco que, a su vez, resulta en una mala prescripción, como lo expone Bell (2000), pero incluso cuando el diagnóstico fuera el adecuado, el "agente activo", en el contexto actual resulta complicado que las libres fuerzas del mercado puedan generar una demanda de fuerza de trabajo suficiente para abatir el grado de desempleo; por lo tanto, ante tal disyuntiva se hace necesaria la intervención del gobierno para ofrecer oportunidades de empleo a todo aquel que sea capaz, esté listo y dispuesto para ocupar una plaza laboral con un salario determinado, es decir, el gobierno podría constituirse como empleador de último recurso mediante un programa público de empleo (PPE).

Sin embargo, no es sencillo que en la actualidad y en economías como la mexicana se acepte nuevamente el regreso del gobierno como actor principal en el desarrollo económico por las siguientes implicaciones: por una parte, para instrumentar el PPE el gobierno tendría que aumentar su déficit presupuestal, situación poco viable ante la aparente carencia de recursos; ${ }^{3}$ por la otra, la creación de empleos por parte del gobierno podría resultar inflacionaria y, por último, cabrían dudas al respecto de las actividades en las cuales se generarían esas nuevas oportunidades (Wray, 2000b).

1 Se puede argumentar, incluso, que en algunos casos el problema se intensificó con el programa de reformas del cual fueron objeto varios países de Latinoamérica (Stiglitz, 2003).

2 Algunos autores relacionan la pobreza con el desempleo e incluso mencionan que puede mantenerse cuando el desempleo tienda a disminuir, debido a una generación de empleos que se sustenta en salarios bajos y un mínimo de prestaciones (Agenor, 2004). Forstater (2000) afirma que, en el caso de los afroamericanos estadounidenses, puede deberse a la marginación que en materia de trabajo han sido objeto, reflejada en actividades con bajas remuneraciones y nulas prestaciones sociales y laborales. En el caso de México, el Banco Mundial coincide en que, al menos en el caso de la pobreza rural, ésta se debe, entre otras cosas, a que los pobres urbanos están cada vez más limitados al sector informal y, con ello, tienen menos acceso a la protección social.

3 Pero no sólo por el argumento de la carencia de recursos, sino más bien por una idea de mantener equilibrado el presupuesto gubernamental que se ha permeado en la gran mayoría de las economías en el nivel mundial (Wray 2000b). La máxima de finanzas públicas sanas no tiene que ser un fin en sí mismo, pero sí un medio para conseguirlo, como lo argumenta Lerner (1957).

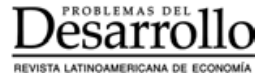


En este documento se asegura que es realmente posible que el gobierno pueda constituirse como empleador de última instancia, ${ }^{4}$ eliminando o disminuyendo los altos costos que para la sociedad representa contar con una parte de la población desempleada. Siguiendo con la línea trazada por Lerner (1957), Wray (2000b, 2003), Forstater (1999a, 1999b, 2000, 2005), Mitchell (1998), Mosler (1997) y Bell (2000), se presenta a continuación una posible aplicación que pueda ser evaluada para la economía mexicana.

\section{Fundamentos teóricos de la política pública en la creación de empleos}

Existe la disyuntiva respecto de a quién le corresponde la responsabilidad de crear empleos. En ese sentido, hay quienes piensan que es la iniciativa privada la que debe incrementar su demanda por inversión, reactivando con ello el mercado de trabajo. Pero el problema consiste en que algunas empresas trabajan con sustancial exceso de capacidad, por lo tanto, resulta poco factible pensar que puedan incrementar dicha demanda. Incluso, en el caso de una disminución de la tasa de interés que tenga por objeto incrementar la inversión, esto no tendría el resultado deseado, en virtud de que las decisiones de inversión en el largo plazo dependen de la expectativa de ganancias, ${ }^{5}$ es decir, de aquella percepción de los empresarios de colocar su producción en el mercado.

Las empresas privadas trabajan con capacidades ociosas básicamente por dos razones: la primera de ellas relacionada con el ciclo recesivo de la economía y la segunda, estrechamente vinculada con aspectos estratégicos de las empresas relacionados con el aprovechamiento de las nuevas oportunidades del mercado.

De acuerdo con Kalecki (1973), en un sistema capitalista es frecuente encontrar recursos ociosos. Él mencionaba que el grado de utilización del equipo es muy pequeño durante la depresión, dando como contrapartida el desempleo de la fuerza de trabajo. El argumento para no producir teniendo equipo no utilizado consiste en el poco beneficio que se obtiene, en virtud de que los precios a los cuales se pueden vender los bienes y servicios durante la recesión están por debajo de los costos de producción. En ese caso, la reducción de los salarios podría compensar la relación costo-precio, pero la generalización de la reducción salarial puede operar de manera contraria a la posibilidad de la realización de

4 Es importante aclarar que en la lógica de la generación de empleos por parte del gobierno se han de sarrollado diferentes planteamientos con distintos nombres, como: programa de servicio público de empleo (Forstater, 2005), programa de empleador de último recurso (Wray, 2000a, 2000b), pro grama gubernamental de garantía de empleo (Mitchell, 1998), entre otros. En general, guardan la misma esencia; aun cuando difieren un poco en sus características, dichas distinciones no serán objeto de análisis en este documento. Wray y Tcherneva (2005) comentan que gran parte del enfo que del empleo público hace referencia al new deal como experiencia de un programa de creación de empleos.

5 Bell (2000), citando a Minsky, menciona que sobre el horizonte del largo plazo son las expectativas de ganancia las que determina la inversión, más que las disminuciones de la tasa de interés.

\section{DeSarrollo}


los bienes producidos, dada la disminución de la demanda efectiva; ${ }^{6}$ con este argumento se cae en un círculo vicioso del cual las empresas privadas no tendrían la capacidad de salir por sí solas.

Por otra parte, también es posible que las empresas no trabajen a $100 \%$ de su capacidad instalada, por razones estratégicas de posicionamiento de mercado, es decir, ante nuevas oportunidades de mercado, las empresas desearán tener una capacidad ociosa de la cual puedan valerse para aprovechar las nuevas demandas, ya que de no ser así, perderían con respecto de otras que dispongan de la capacidad adicional y estén preparadas para usarla. Forstater (1999a) indica que las empresas desean mantener una reserva para adaptarse a circunstancias cambiantes. Sin embargo, esto no es posible tan sólo con el exceso de capital, sino que también es necesario que exista uno de fuerza laboral desempleada, para que las empresas puedan responder en cualquier momento a dichas situaciones.

En el caso de que las empresas se encontraran ante una situación de completa utilización de su capacidad instalada y de que todos los trabajadores se encontraran empleados, tendrían una restricción al crecimiento, y cualquier intento por incrementarlo tendría como resultado presiones inflacionarias. Con este argumento, para que las empresas privadas puedan aprovechar las oportunidades del mercado necesitan, además de tener capacidad instalada ociosa, contar con un ejército de reserva listo para ser empleado.

Así entonces, para que las empresas puedan encarar los cambios en las condiciones del mercado, es necesario que exista un nivel de desempleo que garantice soluciones a los problemas que ocasiona la inflexibilidad del equipo de capital y la fuerza de trabajo. El conflicto consiste en que la flexibilidad lograda con desempleo tiene altos costos, como son: pérdidas en la producción potencial de bienes y servicios, incremento de los índices de pobreza, menores ingresos impositivos resultantes de una menor actividad económica, aumento del gasto público en la atención de programas sociales, crecimiento de los problemas de carácter social asociados con la pobreza, entre otros (Forstater, 1999a).

Apostar por la inversión privada para generar empleos no es una buena opción en el corto plazo. Por lo tanto, la alternativa que ofrece mayores posibilidades de éxito es la generación directa de empleos por parte del sector público, ${ }^{7}$ ya que en el corto plazo no depende de rendimientos ni de la inflexibilidad o flexibilidad económicas.

$6 \quad$ Kalecki (1973:58 59) argumentaba que la disminución salarial incrementa los beneficios de los capitalistas, por lo tanto, si éstos incrementan su consumo - generalmente cambia muy poco en el ciclo económico- en la misma proporción que los bienes no consumidos por los asalariados, se conseguiría un equilibrio en un nivel más elevado.

7 Realizando una valoración al respecto de tres propuestas para disminuir el desempleo que consistían en: a) el incremento de la inversión pública para alentar la inversión privada; $b$ ) la disminución de la tasa de interés para incentivar la inversión privada, y c) el aumento de incentivos a trabajar tanto de empresas y trabajadores. Bell (2000) concluye que la creación directa de empleos por parte del gobierno es quizá la mejor opción, por los efectos que ésta tendrá en el incremento de la demanda del mercado y con ello de las expectativas del sector privado. 
Es importante recordar que una de las responsabilidades de cualquier gobierno es garantizar la generación de empleos, ${ }^{8}$ ya sea de manera indirecta mediante el estímulo de la actividad privada o de manera directa, siendo él mismo un empleador más. Ello no debe de traducirse como una propuesta dirigida a la creación de una economía planificada de corte socialista, sino como un paso necesario que cualquier Estado debe llevar a cabo. En la medida que la economía logre retomar ritmos de crecimiento, las plazas de trabajo creadas por el gobierno irán dando paso a las nuevas oportunidades de empleo en la iniciativa privada.

El PPE por parte del gobierno no debe tener la expectativa de crear empleos permanentes; los empleos generados deben tener un carácter temporal, siendo la reactivación económica la que determine la duración de los mismos. ${ }^{9}$ La movilidad de la fuerza laboral se irá dando mediante la búsqueda de mejores salarios en comparación con los que pague el gobierno; así las empresas, ante mayores expectativas de realización de sus bienes y servicios en el mercado, estarán en condiciones de ofrecer mejores salarios que los del sector público y, con ello, se dará una disminución de trabajadores al servicio del Estado.

La lógica en la cual se sustenta la suposición de la movilidad de los trabajadores del sector público al privado consiste en el establecimiento de un salario mínimo para las personas que sean objeto del PPE. La propuesta tiene la ventaja de que dicha movilidad se daría del sector público al privado en lugar de darse del desempleo al empleo o, incluso, de la informalidad a la formalidad. Adicionalmente, establecer un salario mínimo para aquellas personas que estén listas, sean capaces y estén dispuestas a ser contratadas puede funcionar como un estabilizador del nivel de precios.

Con base en estos argumentos, se destaca la necesidad de la participación del Estado en la reducción o eliminación del desempleo. Sin embargo, aun cuando se pueda aceptar y validar la presencia activa del Estado en la creación de empleos, parece razonable cuestionar la procedencia de los recursos necesarios para la instrumentación del PPE y saber si el Estado cuenta con ellos o si bien estarán asociados al incremento en el déficit presupuestal.

8 Musgrave y Musgrave (1995) resaltan que al hablar de la política fiscal, ésta debe considerar al menos tres funciones que son básicas: la asignación, la distribución y la estabilización. En lo correspondiente a la última de ellas, ésta tiene la responsabilidad de garantizar el crecimiento económico, la disminución del desempleo y la estabilización de precios. Stiglitz (2003), por su parte, menciona que tener un empleo debería de ser un derecho fundamental de todo miembro de la so ciedad y, por lo tanto, el gobierno tiene la obligación de garantizarlo y en caso de fracasar, debería perder su mandato.

9 Forstater (2005) menciona que un programa público de empleo actúa como fuerte estabilizador automático, en virtud de que el déficit crece cuando la economía se contrae y diminuye cuando la economía se expande.

\section{DeSarrollo}




\section{El programa público de empleo y el déficit presupuestal}

Es lógico pensar que con la instrumentación del PPE el gobierno tendría necesariamente que incurrir en un incremento del déficit para hacer frente a los gastos, pero en términos generales, el incremento puede ser menor de lo que se piensa. Si parte de los recursos empleados actualmente en programas de carácter social ${ }^{10}$ se canalizaran a incentivar la actividad económica, se tendría bajo impacto en el déficit, con la ventaja de que la nueva asignación de recursos permitiría avanzar en acciones de inversión pública que podrían redundar en mejoras de la rentabilidad de los agentes privados. ${ }^{11}$ No obstante, los resultados podrían no ser los deseados en materia de reactivación económica, ya que los recursos se estarían redistribuyendo pero seguirían siendo los mismos; para que se diera una reactivación económica que permitiera avanzar en la disminución del desempleo, probablemente se tendría que recurrir a cierto grado de déficit presupuestal. ${ }^{12}$

Para el caso de Estados Unidos, Wray (2000a) reconoce que la política propuestal puede conducir a incrementar el déficit y que éste puede incluso resultar persistente, pero argumenta que ello no debe ser visto con horror. El déficit no causa el desplazamiento de la inversión privada por la pública, no incrementa necesariamente la carga de la deuda a generaciones futuras ni debe ser considerado la ruina financiera del gobierno, como es constantemente argumentado por los economistas de corte liberal, adeptos del Consenso de Washington y de las políticas fondomonetaristas. Además, el déficit se deberá incrementar tan sólo hasta el punto en el cual el desempleo voluntario sea eliminado; de esa manera se asegura que el incremento no sea excesivo.

Lamentablemente, en el contexto de política económica que somete al país a trabajar con disciplina fiscal, resulta poco atractivo proponer acciones que signifiquen incurrir en déficit presupuestal; así, parece imposible realizar lo que técnicamente es posible. Se supone que, en el mainstream, el gobierno debe limitarse al uso de los recursos que le son entregados por concepto de impuestos, por lo tanto, no puede incrementar su gasto si no es

10 Para economías como la de Estados Unidos que cuentan con programas de seguros de desempleo, se piensa que el costo puede ser menor, ya que, en lugar de canalizar esos recursos al desempleo, se llevaría al empleo y así los citados programas podrían ser disminuidos o eliminados (Wray, 2000a).

11 Existe buena cantidad de estudios en los cuales destaca que el gasto en inversión pública por parte del gobierno incrementa la productividad del sector privado, y con ello se incrementan las ganancias, se propicia mayor inversión y se crean más empleos (Aschauer, 1988, 1989a y 1989b).

12 En ese sentido, Arestis y Sawyer (2003) argumentan que el tamaño del déficit debería estar deter minado por la cantidad de desempleo existente, es decir, que si todavía se tiene algún nivel de desempleo sería necesario incrementar el déficit presupuestal. Los autores adicionan que se podría establecer una regla de política que consistiría en incrementar o disminuir el déficit presupuestal de acuerdo con el aumento o disminución del desempleo en la economía. En el mismo orden de ideas, Forstater (1999a) menciona que el programa debe asegurar que el déficit sólo crezca hasta el punto en que todo el desempleo involuntario es eliminado.

\section{DeSarrollo}


mediante el incremento de su recaudación. ${ }^{13}$ Con esta restricción, se equipara al Estado como una empresa privada sin acceso al dinero o, lo que es lo mismo, se desconoce su soberanía para crearlo. ${ }^{14}$ En el caso de una nación soberana, con el derecho de emitir moneda, la impresión de dinero es una alternativa a la imposición de contribuciones como fuente de ingresos que puede ser ilimitada, siempre y cuando su costo de emisión sea cercano a cero, con la única restricción de ser aceptada por la población. ${ }^{15}$

En algunos documentos acerca del origen de la moneda se ha discutido que el dinero es una criatura del Estado (Lerner, 1947), pero si partimos de que se usa para pagar bienes, mercancías o servicios, una de las condiciones básicas para cualquier bien que represente ese papel en una economía es su aceptación general. ${ }^{16}$ El Estado moderno, en teoría, podría elegir cualquier bien o mercancía generalmente aceptada como dinero, independientemente de la conexión que pudiera tener con algún otro material (por ejemplo, el oro). ${ }^{17}$

La aceptación por el dinero del Estado se da, de acuerdo con Lerner (1947), en la secuencia siguiente: si el Estado, de buena voluntad, acepta la cosa propuesta como dinero en el pago de los impuestos y alguna otra obligación, "la trampa está hecha": todos aquellos que tienen obligaciones con el Estado admitirán de buena gana los trozos de papel con los cuales pueden resolver sus obligaciones y todas las demás personas lo harán también porque en algún momento serán contribuyentes. Si el Estado declinara su aprobación por algún tipo de dinero, resulta poco sencillo entender en cuál mecanismo las personas seguirían autorizándolo de manera general. La única situación en que otras formas de dinero, como los cigarros o la moneda extranjera, puedan ser ampliamente usados ocurre

13 Parguez (2002) realiza una crítica a los principales postulados de la ortodoxia fiscal, indicando que desde esta visión se le exige al Estado no ejecutar déficit presupuestal, e incluso debe de preocuparse por generar superávit; con esa exigencia el Estado se ve limitado a gastar únicamente lo que genera mediante la recaudación tributaria o, incluso, en algunos casos, que su gasto sea menor a su recaudación; para algunos economistas de filiación poskeynesiana, la búsqueda del superávit presupuestal tiene una connotación similar a la destrucción del dinero por parte del Estado, con las implicaciones que ello generaría (Wray, 1999).

14 El dinero es una criatura del Estado (Forstater, 1999b); cualquier persona que tenga que cumplir con el pago de contribuciones estará deseosa de aceptar el dinero para ello y, a su vez, todas las personas lo aceptarán como medio de transacción.

15 El costo del dinero en una economía moderna es muy cercano a cero, porque el dinero tan sólo tiene un valor nominal, a diferencia del patrón oro, en el cual el valor del dinero era intrínseco, pero incluso en el caso del patrón oro, el gobierno podía obtener alguna ganancia al degradar la moneda (Wray, 2000c) y obtener beneficios con el impuesto de señoreaje.

16 Bell (1998a), citando a Minsky, menciona que cualquiera puede crear dinero; el problema es conseguir su aceptación por parte de los demás.

17 La teoría del chartalist, expuesta por Knapp, es una aproximación anterior al papel que juegan el Estado y el dinero en la economía. En este desarrollo, Knapp expone que sería imposible separar la teoría del dinero de la del Estado (Wray, 1998a). El chartalist reconoce el poder del Estado para demandar la realización de determinados pagos y la determinación de los medios en los cuales dichos pagos deberán realizarse (Bell, 1998a). 
cuando la economía está en caos. ${ }^{18}$ Para Wray (1998b), cuando el Estado está en crisis y pierde su legitimidad, y en particular su capacidad de gravar y hacer cumplir las deudas tributarias, el dinero normal estará en un estado de caos que conduce al uso de moneda extranjera en las transacciones domésticas privadas.

La función de la tributación por parte del Estado tiene el objetivo de crear demanda por la moneda de curso legal (fiat money) ${ }^{19} \mathrm{y}$, con ello, asignarle un valor. Los impuestos, de acuerdo con Goodhart (1998), no hacen y no pueden financiar el gasto gubernamental; el Estado necesita que el sector privado demande el dinero para poder asignarle un valor. Si no se contara con un sistema efectivo de recaudación tributaria, el valor de la moneda rápidamente caería a cero. Así, los impuestos, en vez de generar recursos para el Estado, tienen la función de generar demandas por el dinero que en la sociedad se hace, no por las disposiciones legales que son decretadas por el gobierno ni porque dicho dinero esté soportado o respaldado en algún metal precioso (oro o plata) ${ }^{20}$ sino por el poder que tiene el Estado de hacer cumplir a la sociedad con sus obligaciones fiscales y, sobre todo, porque se reserva el derecho de decidir qué cosa será aceptada para el pago de las mismas, es decir, qué tipo de bien denominado dinero será admitido en las oficinas recaudadoras (Wray, 1998b). En ese sentido, se habla de dinero soberano cuando:

[...] el gobierno no promete convertir su moneda a oro (u otro metal precioso) o a una moneda extranjera a un tipo de cambio fijo [...] el gobierno debe ser capaz de imponer contribuciones sobre su población que son denominadas en la misma moneda. Por lo tanto el dólar en Estados Unidos y el yen en Japón son ejemplos de moneda soberana. Cuando Argentina operaba con el consejo monetario, no tenía moneda soberana (Wray, 2003).

18 Mankiw (1997:190) comenta que en los campos de concentración nazis, durante la segunda guerra mundial, surgió una clase excepcional de dinero: dado que la cruz roja suministraba a los prisioneros diversos bienes, la asignación no consideraba las preferencias personales por lo cual se suscitaba el trueque entre ellos. Sin embargo, la forma de intercambio resultaba difícil en virtud de que debía existir una doble coincidencia de deseos. En esta situación, los cigarrillos se convirtieron en moneda corriente, incluso aquellas personas que no fumaban los aceptaban porque sabían que sería fácil intercambiarlos por otros bienes. Dentro de los campos de concentración los cigarrillos se convirtieron en depósito de valor, unidad de cuenta y medio de cambio. Mankiw también menciona que en los últimos años de los ochenta, en la economía de la Unión Soviética se preferían los paquetes de Marlboro al rublo.

19 Wray (1998a:77) argumenta que todas las economías capitalistas modernas trabajan con fiat money, el cual tiene las siguientes características: funciona como moneda de curso legal, esto es, es sancionada por la corte como moneda que sirve para cumplir con todas las deudas públicas y privadas; es la única moneda aceptada para el pago de los impuestos; es la moneda en la cual las obli gaciones bancarias son convertibles y es usada para limpiar la cantidad bancaria entre los bancos y el banco central; es la usada como liga entre los pagos públicos y privados; se posa encima de la pirámide de deuda; es la obligación líquida más usada. En una economía moderna normalmente funcionando, el fiat money es siempre aceptado como cambio por productos domésticos; cualquier cosa que esté a la venta con precios en dólares puede ser entregado por dólares.

20 Con el abandono del patrón oro se había eliminado también la barrera que existía para el uso de políticas de pleno empleo (Wray, 2000a). 
El gasto público pone en circulación el dinero de curso legal, es el mecanismo por el cual se oferta el dinero del Estado, aun cuando en algunos casos el banco central pueda realizar operaciones directas de compra de bienes y servicios o las operaciones de mercado abierto no resultan suficientes para introducir en la economía la cantidad de dinero necesaria para que la población cumpla con sus obligaciones fiscales o para acumular ahorros en ese activo.

El Estado no necesita dinero de los particulares para gastar; son éstos quienes necesitan el dinero del Estado para poder cumplir con sus obligaciones fiscales. El proceso de imposición y gasto debería tener una secuencia lógica:

- El gobierno empieza creando y gastando dinero.

- Los agentes económicos privados que realizan actividades y transacciones en la economía deben de cumplir con obligaciones fiscales, debidamente gravadas por el gobierno.

- El dinero creado por el gobierno es el único aceptado en el cumplimiento de las obligaciones fiscales de los agentes económicos privados, por lo tanto, para cumplirlas deben contar con dicho recurso.

¿Cómo podría la población cumplir con sus obligaciones fiscales usando el dinero del Estado antes de que éste lo hubiera creado y puesto a su disposición? (Bell, 1998b). Las compras del gobierno en bienes y servicios, además de incrementar la cantidad de dinero de curso legal (Wray, 2001), ${ }^{21}$ proporcionan a la población los medios necesarios para que realicen el pago de impuestos y, al hacerlo, es como si se destruyera el dinero del Estado.

Cuando el gobierno compra bienes y servicios mediante la creación de dinero de curso legal, se genera una creación neta de dinero; ya que no está compensada con pasivos del sector privado, el dinero neto está disponible para pagar impuestos. Cuando ello se realiza se reduce la tenencia de dinero neto, por lo tanto, el gasto debe anteceder al ingreso. El equilibrio fiscal, ampliamente buscado por los economistas convencionales, es poco probable que sea de carácter continuo e incluso, en el caso de ejecutar superávit presupuestal, los agentes privados, para cumplir con sus obligaciones fiscales, tendrían que reducir la acumulación de dinero neto que lograron en ejercicios fiscales anteriores en los cuales el gobierno hubiera operado déficit presupuestal (Wray, 1998a:78-80). Si los agentes económicos tuvieran el deseo de acumular ahorros en dinero de curso legal (fiat money), ello tan sólo sería posible en aquellos casos en los cuales el gobierno ejecutara déficit presupuestal, pues en finanzas sanas se estaría retirando (destruyendo) la misma cantidad de dinero neto que el gobierno suministra a la economía.

Como se puede apreciar, en el contexto de soberanía monetaria el gobierno no está restricto a la recaudación de ingresos tributarios para poder incrementar su gasto, por lo

$\overline{21}$ Wray se referiría al dinero $d e$ curso legal como dinero de alta potencia.

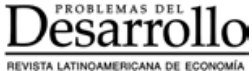


tanto, aun cuando el PPE pudiera estar ligado al incremento del déficit presupuestal, esto no sería una limitante real. ${ }^{22}$ Técnicamente es posible, ${ }^{23}$ pero queda todavía una crítica que puede ser razonable y que es necesario abordar: el PPE en algún momento podría incidir en el incremento del nivel de precios, es decir, ¿podría ser inflacionario?

\section{Fundamentos antiinflacionarios del programa público de empleo}

Cuando el nivel de gasto general en la economía es bajo, se registrará desempleo, mientras que un nivel demasiado alto tendrá como consecuencia inflación, por lo tanto, es necesario conseguir un nivel de gasto en el cual se consiga el pleno empleo, ${ }^{24}$ definiendo éste como el nivel en el cual un aumento del gasto general conducirá a una espiral inflacionaria derivada del incremento en los salarios y el nivel de precios.

El proceso de una espiral inflacionaria puede darse por la presión de los trabajadores por obtener salarios más altos. Si la economía se encuentra cerca del pleno empleo, la presión de los trabajadores para aumentar sueldos es mayor que la resistencia de los patrones para hacerlo, dando por resultado un crecimiento en los salarios mayor que el de la productividad. "Los patrones se sienten reacios a interrumpir la producción, por que los negocios marchan muy bien y no se encuentran fácilmente otros obreros. Incluso puede que los patrones fuercen los salarios al alza, en un intento de rápida expansión, para sacar partido del relativo buen estado de los negocios. Así aumentan lo salarios (Lerner, 1957:167)".

Así, se dará un incremento en los salarios, pero tendrán su contraparte en el costo de los factores, el cual se verá expresado en el precio. La capacidad de aumentar los precios es un elemento importante para que los patrones decidan elevar los salarios. Sin embargo, el crecimiento de los precios deja de lado el salarial y es posible que se busque con los mismos resultados.

22 De hecho, la limitante real se sitúa en la pérdida de la soberanía de la política monetaria y fiscal, pérdida que en ciertos aspectos es autoimpuesta por el mismo gobierno para satisfacer los intereses de los agentes económicos internacionales, quienes ante la presencia de presiones inflacionarias y variaciones en el tipo de cambio, pierden el interés por mover sus capitales al país. Es así como se privilegia una política económica restrictiva por mantener la entrada de divisas. Un desarrollo amplio del tema se puede revisar en Huerta (2004).

23 Siempre y cuando se pueda tener el manejo de la moneda, es decir, si se opera con moneda soberana, ya que de no ser así, de acuerdo con Wray (2003), es posible que no se pueda ofrecer un programa de empleo público; de hecho, una condición necesaria para instrumentarlo consiste en trabajar en un régimen de tipo de cambio flotante (Forstater, 2005).

24 Al respecto, Keynes (2003:278) mencionaba que cuando la demanda efectiva resulta deficiente, se origina subempleo de la mano de obra, ya que hay hombres dispuestos a trabajar; a medida que dicha demanda se incrementa, también lo hace la ocupación. 
El aumento en los precios anula los beneficios que los trabajadores esperan obtener de la elevación de los salarios: no pueden comprar más servicios que antes, con lo salarios más bajos. Esto origina otra petición de aumento de jornales que proporcione a los trabajadores el esperado aumento de lo salarios reales, aumento que estiman se les ha escamoteado con la elevación de los precios; el nuevo aumento de salarios conduce a una nueva elevación de precios, a otra desilusión y a otra petición de aumento de salarios. De esta forma se engendra la espiral de la inflación (Lerner, idem).

La espiral inflacionaria ocurre con la creencia de una situación de pleno empleo. Sin embargo, éste, a diferencia de la idea neoclásica, no es un estado perpetuo ni al cual se llega de forma natural, sino de forma accidental o, bien, con el uso de políticas adecuadas, ${ }^{25}$ como puede ser el PPE.

El supuesto de llegar a una situación de pleno empleo en un régimen capitalista es poco defendible, ya que los niveles de producción no están determinados por las capacidades productivas, ${ }^{26}$ sino por la posibilidad de venta o demanda efectiva. En dicho sistema es frecuente encontrar recursos ociosos. ${ }^{27} \mathrm{El}$ pleno empleo no debe ser entendido como una posición en la cual todas las personas ocupan una vacante laboral. Para Lerner (1957:14) significa que quienes quieren trabajar a los tipos corrientes de remuneraciones, pueden encontrar trabajo sin dificultades indebidas. Para entender a qué se refiere, Lerner hace una distinción entre el desempleo friccional y aquel que tiene que ver con la deflación: en el primer caso, el desempleo se da por la falta de correspondencia entre personas sin empleo y los empleos vacantes, mientras que en el segundo caso se da por la falta de una cantidad de empleos suficientemente disponibles.

La solución para eliminar el desempleo deflacionario consiste en tomar medidas para aumentar el gasto total en la economía, pues ese tipo de desempleo se da por la cantidad exigua de demanda por trabajadores, que es consecuencia de un gasto insuficiente. Por su parte, el desempleo friccional no se soluciona con tan sólo incrementar el gasto en la economía; se deben adoptar medidas canalizadas a eliminar las fricciones que lo ocasionan.

De acuerdo con Lerner (1957:16-17), cuando el número de personas es mayor al número de vacantes, un incremento en el gasto total elevará la cantidad de vacantes y cada vez que éstas aumenten, también aumenta el desempleo friccional, porque se desasocia el perfil de la vacante con el del individuo desempleado. Por lo tanto, el efecto del gasto

25 Para el caso de Estados Unidos, Wray (1997) comenta que salvo por un breve periodo correspondiente a la guerra de Vietnam, la economía ha operado por debajo del pleno empleo. Entre 1959 y 1993 el promedio de la tasa de capacidad utilizada en la manufactura fue de tan sólo $82 \%$ y alcanzó cerca de $85 \%$ sólo dos veces desde 1974, sin llegar nunca a 85.5\%, el cual es considerado situación de pleno empleo.

26 El profesor Julio López menciona que las capacidades productivas están determinadas por la dotación de los medios de producción y la eficacia con la cual se utilizan, así como por la cantidad y grado de adiestramiento de la fuerza de trabajo.

27 Como se comentó con anterioridad, en algunos casos no trabajar a 100\% de la capacidad instalada responde a estrategias de mercado que tienen las empresas.

\section{DeSarrollo}


total se torna nulo para crear más empleos y es posible que ocurra un proceso inflacionario, pues en lugar de aumentar el empleo, crece el nivel de salarios y precios como resultado de una lucha entre los empresarios por ocupar sus nuevas vacantes con trabajadores que cumplen debidamente los requisitos solicitados, pero que ya tienen empleo.

El desempleo friccional puede ser traducido como la tasa natural de desempleo, es decir, aquella en la cual no se generan presiones inflacionarias, lo que significa que cualquier intento por disminuirla causa inflación. No obstante, Wray (2000d) argumenta que la tasa natural de desempleo podría llevarse a cero siempre y cuando el gobierno tenga la capacidad de decidir qué va a comprar. ${ }^{28}$

Desde luego que la función del gobierno será tratar de romper tanto con el desempleo por deflación como con el desempleo friccional, teniendo que establecer estrategias diferentes. Se sabe que en las economías en vías de desarrollo se observa un desempleo importante de la fuerza de trabajo y una constante disminución de la actividad productiva en ciertos sectores. En ese contexto, si en la economía tenemos capacidad ociosa y el gasto de gobierno se dirige a incentivar esos sectores, tendremos por resultado un incremento en la producción que compense el incremento de la demanda sin que se den presiones en el nivel de precios. Por el contrario, si el gasto de gobierno no es dirigido a esos sectores, es muy probable que, en efecto, se presente una situación de incremento de precios.

El gasto gubernamental en todos los casos debe ser minuciosamente seleccionado. ${ }^{29}$ Resulta de vital importancia que el gasto realizado no se quede en simples erogaciones de carácter corriente, ya que éstas no representan una contribución significativa a la producción futura y menos a la inversión inducida. ${ }^{30}$ Los gastos necesarios y de mayor valía estarán relacionados con un incremento en la capacidad productiva; gasto intensivo en mano de obra neutral al mercado de divisas; orientación de demanda derivada de la inversión pública hacia los bienes que puedan ser elaborados en el mercado local; la transferencia en el pago de la deuda debe ser disminuida o renegociada, entre otros. La aplicación del gasto gubernamental es un elemento fundamental en la consecución del pleno empleo y, dependiendo de hacia dónde se canalice, será su posibilidad de tener resultados inflacionarios.

28 Wray, refiriéndose al caso de Estados Unidos, menciona que si el gobierno intenta alcanzar el pleno empleo encargando misiles de alta tecnología con seguridad, en lugar de disminuir la tasa natural de desempleo, sería mayor a diferencia de la utilización de mano de obra no especializada.

29 Lascano (1988) menciona que la selección del gasto debe ser minuciosa aun en aquellos casos en los cuales la desocupación tenga magnitudes considerables, ya que de lo contrario, se tendrán presiones inflacionarias, al ajustarse precios más que cantidades.

30 Kalecki (1973:69) comenta "que lo que determina esencialmente los efectos de la intervención del gobierno no es la clase de inversión pública realizada, lo que realmente importa es que la inversión se financie mediante la creación de poder adquisitivo adicional". Desde luego que esta apreciación es correcta para una economía desarrollada en una coyuntura de recursos ociosos, pero puede no serlo necesariamente para una en desarrollo, en la cual el gasto tiene que canalizarse de forma estratégica.

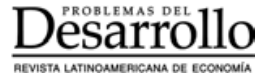


Hasta el momento se han revisado las implicaciones que puede tener el incremento de la demanda en las presiones inflacionarias, pero falta abundar en los efectos que puede tener el pleno empleo en la inflación como resultado de presiones en los salarios y en costos y precios. A tal respecto, el precio pagado por el gobierno a todo aquel que quiera trabajar es determinado de manera exógena, es decir, el gobierno, de forma arbitraria, delimita el salario al que contratará a un específico número de personas; en ese sentido, su decisión dependerá de qué cantidad de trabajadores desee contratar. ${ }^{31}$ Si el salario del programa se establece muy bajo, es probable que el número de personas que deseen trabajar por esa remuneración sea menor, mientras que a medida que se vaya incrementando, cada vez serán más las personas que estén deseosas de contratarse en él. De hecho, si el gobierno se compromete a contratar a todas las personas que así lo soliciten, en ese momento se estará fijando un mínimo salarial.

muchos trabajos de bajos salarios que pagaban menos que el programa antes de que fuera instrumentado, experimentarán al mismo tiempo un incremento en sus salarios (o desaparecerán en conjunto), los empleadores serán forzados a cubrir los altos costos del trabajo a través de una combinación de mayores precios de productos, mayor productividad del trabajo y menor realización de ganancias (Forstater, 1999a).

Se podría pensar en una escalada de precios que resultará inflacionaria, como resultado del incremento de los salarios, pero en la medida que el gobierno mantenga constante ese piso salarial se pueden evitar posibles efectos de espirales inflacionarias e incluso Wray (2000d) sugiere:

si el salario [...] se fija en un nivel de salario mínimo, ni siquiera ocurrirá ese salto, por eso tal vez sea menos perturbador que al principio se fije el salario [...] en el nivel del salario mínimo y sin las prestaciones. Fijarlo por arriba del salario mínimo e incluir prestaciones causará al principio que los trabajadores del programa crezcan, pues el sector privado perdería trabajadores. Este sector tendría entonces que elevar los salarios y las prestaciones, supuestamente forzándolos a elevar los precios. Pero este salto de una sola vez no es inflacionario ni puede ser inflación acelerada según los términos en que los economistas suelen definirlas.

Como podemos observar, una política dirigida a lograr la plena ocupación de la mano de obra no tiene por qué ser inflacionaria. La inflación puede coincidir con el PPE, pero no es originada por él y, en algunos casos, de acuerdo con Wray (2000a), puede incluso constituirse como estabilizador automático que elimine las fluctuaciones del ciclo económico.

\section{La creación de empleos del programa}

Resulta necesario tener presente en qué actividades y tipos de empleos debería incursionar el gobierno mediante su PPE. Para países como Estados Unidos se ha argumentado que la

31 Sería ideal pensar que el salario se fijaría, en todo caso, por encima de la línea de la pobreza.

\section{DeSarrollo}


creación de empleos con alto contenido social puede ser buena alternativa y se han manejado varias propuestas de posibles actividades que deberían ser consideradas en la creación de nuevas fuentes de empleo. Forstater (2000) argumenta que se debería emplear a individuos con mínima adicción por la burocracia, agregando una oferta de trabajo organizada para proveer necesidades públicas y servicios sociales que alienten la calidad de vida en la población.

De hecho, no se requiere gran imaginación para proponer una innumerable lista de actividades a las cuales se podrían dedicar los beneficiarios del PPE y, a decir de Wray (2000a), en el peor de los casos los individuos estarán cambiando parte de su tiempo por dinero del Estado, situación que puede ser mejor que dar el dinero por nada. Por una parte, tenemos aquellas actividades que son responsabilidad del Estado y no dependen de la existencia de programas de empleo, actividades básicas para el desarrollo de una nación como la creación, conservación y mantenimiento de la infraestructura pública y los servicios que son estrictamente de su competencia. Por otra parte, tenemos aquellas actividades que aun cuando no sean consideradas de su competencia directa, ayudan en mucho a las actividades de los unidades económicas privadas, por ejemplo, en el último de los casos, el gobierno podría tener una parte de los beneficiarios del programa en procesos de capacitación debidamente coordinados con las necesidades del mercado y no como sucede en la educación universitaria, en la cual la oferta y demanda están altamente desasociadas.

Se tiene que redefinir el rumbo, que es lo que debe intentarse, así como seguir con los programas sociales que ayudan a las familias a superar la ignominia o, bien, se les debe ofrecer trabajo para que sean los responsables de consolidar su futuro, apoyados en las adecuadas políticas del gobierno.

En Argentina se estableció un programa de creación de empleos que, en cierta medida, toma como base el programa de empleo público ${ }^{32}$ desarrollado por la Universidad de Missouri-Kansas City y asociados (Wray, 2005). El programa decretado por Argentina el 3 de abril de 2002, denominado Plan Jefas y Jefes de Hogar, se fundamentaba en el artículo 75 de su Constitución Nacional, en la cual se reconoce el derecho familiar a la inclusión social y, por lo tanto, el principal objetivo del programa consistía en asegurar un ingreso mensual a todas las familias argentinas (López y Paz, 2003).

La inclusión social se pretendía lograr mediante una transferencia directa de 150 pesos argentinos ${ }^{33}$ por cada titular y podía ser compatible con la percepción por parte de alguno de los miembros del grupo familiar de becas estudiantiles o transferencias de otros programas sociales por montos menores o ayudas alimentarías (CELS, 2003). A cambio de la transferencia, los beneficiarios se comprometían a ofrecer una contraprestación que consistía en la realización de alguna tarea o acción considerada en los siguientes puntos: a) actividades o proyectos comunitarios, $b$ ) terminalidad del ciclo educativo formal

\footnotetext{
32 En sus diversas modalidades.

33 Equivalentes a 50 dólares estadounidenses (Golbert, 2004).
}

\section{DeSRarrollo}


(primaria/secundaria), $c$ ) acciones de formación profesional, $d$ ) incorporación a una empresa por medio de un contrato formal. La participación en esas actividades no debería de considerar una duración menor de cuatro horas diarias (Plan Jefas y Jefes de Hogar desocupados, Manual de Instrucciones para Municipios y Consejos Consultivos). La realización de la contraprestación es obligatoria para los beneficiarios del plan y su incumplimiento da lugar a la extinción del derecho de percibir el beneficio económico (CELS, 2003). Se han realizado críticas al programa, las cuales tienen que ver con niveles de corrupción y mala administración que impiden que los beneficios realmente lleguen a quienes más lo necesitan (Galasso y Revallion, 2003), además de que en muchos casos no se cumplía con la contraprestación.

El programa de Jefas y Jefes de Hogar en Argentina es un buen intento que busca incrementar el nivel de ingresos de las familias, pero se queda corto en el establecimiento de un programa de empleo público dirigido al logro del pleno empleo; con ello no se sugiere que sea malo, ya que ha logrado llegar a una cobertura de dos millones de familias (López y Paz, 2003), pero en la medida en que no se cumple la contraprestación puede ser visto como un programa de seguro al desempleo o dado el nivel de horas mínimas exigidas se cae nuevamente en el subempleo. La experiencia Argentina es interesante pero tiene algunas oportunidades de mejora.

\section{La posibilidad de México de instrumentar un programa público de empleo}

Como se mencionó, un requisito necesario para llevar a cabo el PPE consiste en el manejo de una moneda soberana que no esté sujeta a la promesa de cambio por algún metal precioso o por alguna divisa. Si un país cualquiera cuenta con esta característica, en cualquier momento puede establecer un PPE, ya que no tendrá dificultades para incrementar su gasto gubernamental e incurrir en el déficit que sea necesario para instrumentarlo. Desgraciadamente México, al igual que otros países de Latinoamérica, se ha autoimpuesto la necesidad de mantener una política fiscal equilibrada ${ }^{34}$ y una política monetaria sólida, con el objetivo de mantener la estabilidad de los precios.

A decir de Wray (2002), México es una nación independiente con la capacidad de emitir una moneda soberana. Cuando el gobierno gasta, es capaz de inyectar a la economía dinero de alta potencia que se denomina en pesos; estos recursos llegan al sistema bancario e incrementan la cantidad de reservas, mientras que la imposición tributaria actúa de forma inversa, tal como se había argumentado en apartados anteriores. El gobierno tam-

34 Incluso países ricos en recursos, como Ecuador y Bolivia, que tienen la posibilidad de pedir préstamos a ventas futuras y con ello generar recursos, fueron obligados al logro de las finanzas públicas sanas, aun en contra de su propio crecimiento; todo ello en el contexto de las reformas iniciadas en la década de los ochenta (Stiglitz, 2003).

\section{DeSarrollo}


bién podría drenar estas reservas mediante una acción conjunta con el Banco de México, vendiendo bonos gubernamentales y con ello estaría manejando la tasa de interés de muy corto plazo $^{35}$ al nivel que se considerara necesario. De no llevarse a cabo la venta de los bonos, el exceso de las reservas llevaría la tasa de interés a cero; así, son las acciones conjuntas de las autoridades fiscales y monetarias las que determinan las tasas de interés de muy corto plazo.

Un gobierno soberano no necesita pedir prestado en su propia moneda con el fin de gastar. Si se emite deuda denominada en pesos, debería de ser tan sólo para drenar el exceso de reservas del sistema bancario y lograr con ello la tasa objetivo de muy corto plazo. El problema con la deuda denominada en otra moneda consiste en el temor de que la creación de dinero neta por parte del gobierno pueda poner en peligro la relación cambiaria y, por lo tanto, la capacidad de cumplir con sus obligaciones en moneda extranjera. Adicionalmente, las decisiones en materia de tasas de muy corto plazo pasan a depender del objetivo de tasa que se piense pueda mantener la relación cambiaria.

Con el objetivo de mantener un tipo de cambio apreciado, el país se somete a operar con política fiscal equilibrada y política monetaria de altas tasas de interés de muy corto plazo, que resultan contraccionistas al afectar directamente el crecimiento económico y la generación de empleos. La situación se ve agravada, pues a medida que el país opera con una moneda fuerte, los bienes domésticos son más caros para los extranjeros, siendo los bienes extranjeros más baratos para los residentes domésticos. Lo anterior conduce a un incremento de las importaciones y a un decremento de las exportaciones, generando déficit de comercio exterior. En ese sentido, Ball y Mankiw (1995) mencionan que cuando un país es importador neto de bienes y servicios, tendrá que ser también un exportador neto de valores. En otras palabras, para poder consumir los productos extranjeros tenemos que pagar una cantidad adicional por concepto de intereses. ${ }^{36}$

El tipo de cambio fijo y, en la mayoría de los casos, apreciado conduce a la economía a un círculo vicioso que constantemente reproduce e incrementa los problemas existentes. México es capaz de implantar un PPE si logra disminuir su requerimiento de divisas, que lo obligan a trabajar con un tipo de cambio fijo. Para ello, debe renegociar la deuda externa, regular los flujos de capitales y revisar su apertura comercial para estar en condiciones de dejar flotar su moneda y retomar su política económica soberana. También es necesario revisar y revalorar la autonomía del Banco de México; recordemos que si Argentina pudo instrumentar un programa como el descrito en el apartado anterior, es por el abandono del consejo monetario, además de su negativa a continuar con el pago indiscriminado de su deuda.

35 El término usado por Wray para referirse a lo que se determina tasas de muy corto plazo es overnight, también se podría interpretar como tasa diaria.

36 Claro que sólo por aquella parte correspondiente al déficit comercial. Entre más grande sea éste, el pago por los bienes y servicios del extranjero será más costoso. 
Si Argentina continúa ignorando las cartas y las llamadas telefónicas de sus acreedores y continúa así, puede esperar una recuperación lenta si continúa manteniendo un tipo de cambio flotante y no ejecuta una postura fiscal demasiado estrecha. Exactamente qué tan rápida será su recuperación dependerá del alcance sobre si sus dirigentes reconocen que ahora trabajan bajo un nuevo paradigma: operando con moneda soberana (Wray, 2003a).

¿Cuál es la posibilidad de México? Retomar el uso de su moneda soberna, técnicamente es posible.

\section{Conclusión}

A raíz de la exposición realizada se pueden puntualizar los siguientes elementos:

- Dadas las características de la economía de mercado y a diferencia del pensamiento de los economistas convencionales, es necesaria la participación del gobierno en la economía para propiciar mayores niveles de empleo o, incluso, para erradicar el desempleo involuntario. Para lograrlo, el gobierno debe canalizar debidamente sus esfuerzos en la creación de empleos en actividades que tengan el mayor impacto social y económico. Con ello se generarán las bases para que el PPE dé paso a la generación de empleos privados.

- Un programa público de empleo, cualesquiera que sean sus características, debe ser permanente, cambiando la intensidad del mismo de acuerdo con el ciclo económico, por lo cual se podría argumentar, sin problema alguno, que el programa se puede visualizar como contracíclico, es decir, que en los momento, de recesión económica deberán ser más intensos, mientras que a medida que la economía incremente su crecimiento, la intensidad de los recursos dedicados al programa tendrá que disminuir.

- Si bien la instrumentación del programa puede implicar el incremento del déficit, esto debe ser valorado tan sólo como un medio para alcanzar un fin. Teniendo en cuenta que si el déficit tiene la intensión de acabar con el empleo de manera directa, siempre se tendrá buena referencia para valorar hasta dónde el déficit puede resultar excesivo.

- La idea de que existe una compensación entre la estabilidad de precios y el desempleo puede ser muy peligrosa y nos lleva a dos situaciones: la primera es la aceptación de una tasa de desempleo natural, es decir, considerar que es normal la existencia de una cantidad de trabajadores desempleados; y la segunda, a una pugna de intereses en la cual tenemos dos grupos con objetivos diferentes, los trabajadores desempleados que pugnan por mayores empleos y los inversionistas que desean una tasa de inflación que no altere sus expectativas de ganancia. Por eso, es necesario avanzar en la idea de que puede disminuirse la tasa de desempleo a cero sin que ello incida en mayores niveles de inflación.

- También hay que reconocer que son muchas las áreas que en materia de seguridad pública, social y ambiental están subatendidas y que bien podría ser un camino fértil para las opciones de empleo generadas por el programa.

\section{DeSarrollo}


- Las limitaciones que tiene México para incursionar en un programa de ese tipo consisten en su planteamiento de política económica que lo han llevado a disminuir la capacidad del Estado para responder ante un ambiente globalizado con un panorama cada vez más volátil en el ámbito financiero. Es necesario retomar la soberanía de la política económica; que el Banco de México, aun cuando autónomo, responda a un objetivo dual de crecimiento y estabilidad de precios, mientras que la Secretaría de Hacienda y Crédito Público entienda que los equilibrios fiscales no son en sí el objetivo, sino el crecimiento económico, pues cualquier proceso de estabilización que no lo ofrezca no puede considerarse exitoso.

- Por otra parte, es necesario redefinir el gasto social. Se puede seguir otorgando el dinero a las personas tan sólo por ser pobres o, bien, se puede intentar sacarlas de su pobreza con la creación de fuentes de empleo. La mejor política social siempre deberá estar acompañada del crecimiento económico para que sea sustentable.

- Por último, no hay que perder de vista que las personas desempleadas o subempleadas en economías emergentes como la nuestra resultan un costo demasiado alto. En la medida en que los trabajadores excluidos del sistema laboral van perdiendo sus habilidades y son menos susceptibles de ser contratados, el problema toma un carácter de permanente.

Al respecto del PPE, quedan pendientes al menos dos aspectos de interés que no fueron abordados en este trabajo y que serán objeto de otras investigaciones. En principio, hay que destacar la postura ideológica de los responsables de la toma de decisiones, que impide cuestionarse el modelo actual de liberalización económica y obliga al mantenimiento de políticas económicas restrictivas en las cuales el crecimiento económico y la creación de empleos pasa a depender de variables exógenas, como son el comportamiento económico de Estados Unidos, el incremento en el precio del petróleo y la entrada de capitales.

En un contexto de liberalización económica, se exige trabajar con disciplina fiscal para mantener la estabilidad monetaria y generar expectativas de confianza para el capital extranjero a fin de que ingrese al país y no salga de él. Por tal motivo, el cambio en el manejo de la política fiscal no ésta a discusión en las esferas del gobierno y la propuesta pierde viabilidad no por una cuestión técnica, sino de carácter político. No se desconocen las limitaciones que se tienen y que fueron abordadas de manera sucinta en el último apartado; más bien se hace énfasis en la posibilidad de regresar a un crecimiento económico con características endógenas, el cual puede ser logrado mediante la instauración del PPE.

Por último, el segundo aspecto que requiere un trabajo adicional es determinar la cantidad de recursos necesarios para la aplicación del PPE. Se tendrá que estimar la población objetivo, el salario mínimo del programa y los efectos que éste tendría en las finanzas públicas y el crecimiento económico.

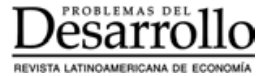




\section{Bibliografía}

Agenor, P., "Unemployment-poverty Trade-offs", en Policy Research, working paper, núm. 3297, Washington, julio, 2004.

Arestis, P. y M. Sawyer, "Reinventing Fiscal Policy", working paper núm. 381, Nueva York, The Levy Economics Institute of Bard College, mayo, 2003.

Aschauer, D., "Is Public Expenditure Productive?", en Journal of Monetary Economics, núm. 23, Elsevier, 1989a, pp. 177-200.

_, "Does Public Capital Crowd Out Private Capital?", en Journal of Monetary Economics , núm. 24, Elsevier, 1989b, pp. 171-188.

, "Is Government Spending Stimulative?", en Sataff Memoranda, Chicago, Federal Reserve Bank of Chicago, 1988.

Ball, L. y N. Mankiw, "What do Budget Deficit do?", working paper núm. 5263, Massachusetts, NBER, septiembre, 1995.

Banco Mundial, "Generación de ingresos y protección social para los pobres", México, agosto 2005.

Bell, S., "Causes and Cures for Unemployment: Assessing the Mainstream View", working paper núm. 08, Kansas City, Center for Full Employment and Price Stability, University of Missouri-Kansas City, julio, 2000.

," "The Hierarchy of Money", Working Paper núm. 231, Nueva York, The Levy Economics Institute of Bard College, abril, 1998a.

- "Can Taxes and Bonds Finance Government Spending?", working paper núm. 244, Nueva York, The Levy Economics Institute of Bard College, julio, 1998 b.

CELS, "Plan Jefes y Jefas ¿Derecho Social o Beneficios sin Derecho?", Buenos Aires, Centro de Estudios Legales y Sociales, mayo, 2003.

Forstater, M., "The Case for an Environmentally Sustainable Jobs Program”, Policy Note 2005/ 1, Nueva York, The Levy Economics Institute of Bard College, 2005.

, "The Full Employment Approach to Reducing Black Poverty and Unemployment in the United States", working paper núm. 07, Kansas City, Center for Full Employment and Price Stability, University of Missouri-Kansas City, marzo, 2000.

, "Public Employment and Economic Flexibility, The Job Opportunity Approach to Full Employment”, Public Policy Brief núm. 50, Nueva York, The Levy Economics Institute of Bard College, 1999a.

, "Functional Finance and Full Employment: Lessons from Lerner for Today?", working paper núm. 272, Nueva York, The Levy Economics Institute of Bard College, julio, 1999b.

Galasso, E. y M. Revallion, "Protección Social en la Crisis: El Plan Jefas y Jefes de Hogar en Argentina", Grupo de Investigación sobre Desarrollo, Banco Mundial, Washington, septiembre 2003.

Golbert, L., "¿Derecho a la inclusión o paz social? Plan Jefas y Jefes de Hogar Desocupados?”, en serie Políticas Sociales, núm. 84, Santiago de Chile, CEPAL, División de Desarrollo Social, abril, 2004.

Huerta, A., La economía política del estancamiento, México, Diana, 2004

Kalecki, M., Estudio sobre la teoría de los ciclos económicos, 2a. ed., Barcelona, Ariel, 1973.

Keynes, J., Teoría general de la ocupación, el interés y el dinero, 4a. ed., México, FCE, 2003

Lascano, M., Política fiscal y dinero, Buenos Aires, Desalma, 1988.

Lerner, A., Economía del pleno empleo, Madrid, Aguilar, 1957.

_. "Money as a Creature of the State", en The American Economic Review, vol. 37. núm. 2, mayo, 1947.

López, P. y J. Paz, "El programa Jefes de Hogar. Elegibilidad, participación y trabajo", documento de trabajo núm. 242, Universidad del CEMA, 2003.

Mankiw, N., Macroeconomía, Madrid, Antoni Bosch, 1997.

Ministerio de Trabajo, Empleo y Seguridad Social, "Plan Jefas y Jefes de Hogar desocupados, Manual de Instrucciones para Municipios y Consejos Consultivos", Buenos Aires, 2002.

Mitchell, W., "The Job Guarantee Model and the NAIRU", working paper núm. 98-01, Centre of Full Employment and Equity, The University of Newcastle, enero, 1998.

Mosler, W., "Exchange Rate Policy and Full Employment", en http://www.mosler.org/docs/ docs/exchange_rate_policy_and_full_em.htm, marzo, 1997.

Musgrave, R. y P. Musgrave, Hacienda pública, teórica y aplicada, Madrid, McGraw Hill, 1995.

Parguez, A., "The Paradox of Fiscal Discipline Policy Into Contemporary Capitalist Economies, An Inquiry Into The Poverty of Nations", Seventh International Post Keynesian Workshop, Kansas City, Missouri, 29 de junio-3 de julio, 2002.

Stiglitz, J., "El Rumbo de las Reformas, Hacia una Nueva Agenda para América Latina", en Revista de la CEPAL, núm. 80, Santiago de Chile, agosto, 2003.

\section{Desaurrollo}


Wray, R. y P. Tcherneva, "Employer of Last Resort: A Case Study of Argentina's Jefes Program", en http://www.mosler.org/docs/docs/Argentina Jefes.htm, enero 2005.

Wray, R., "Is Euroland the Next Argentina?", working paper núm. 22, Kansas City, Center for Full Employment and Price Stability, University of Missouri-Kansas City, febrero, 2003a.

, "Currency Sovereignty and the Possibility of Full Employment", working paper núm. 28, Kansas City, Center for Full Employment and Price Stability, University of Missouri-Kansas City, julio, 2003b.

, "Friedmanian Approach to Restoring Growth", working paper núm. 22, Kansas City, Center for Full Employment and Price Stability, University of Missouri-Kansas City, septiembre, 2002.

, "Understanding Modern Money", Centre of Full Employment and Equity, Workshop, Understanding Unemployment in Australia, Japan and the USA, A Cross Country Analysis, diciembre, 2001.

, "Public Service Employment: Full Employment Without Inflation", working paper núm. 03, Kansas City, Center for Full Employment and Price Stability, University of MissouriKansas City, julio, 2000a.

, "The Employer of Last Resort Approach to Full Employment", working paper núm. 09, Kansas City, Center for Full Employment and Price Stability, University of Missouri-Kansas City, julio, 2000b.

"Funtional Finance and US Government Budget Surpluses in The New Millennium", en http://www.mosler.org/docs/docs/functional_ finance.htm, febrero 2000c.

"Keynes y el pleno empleo: una lectura contemporánea", en Comercio Exterior, vol. 50, núm. 12, México, diciembre, 2000d.

, "Abolish the Surplus", en http://www.mosler. org/docs/docs/abolish_the_surplus.htm, septiembre 1999

, Understanding Modern Money, The Key to Full Employment and Price Stability, Cheltenham, Edward Elgar, 1998a.

, "Money and Taxes: The Chartalist", working paper núm. 222, Nueva York, The Levy Economics Institute of Bard College, 1998b.

, "Deficit, Inflation, and Monetary Policy", en Journal of Post Keynesian Economics, vol. 19, núm. 4, Nueva York, verano, 1997. 